\title{
Familial isolated pituitary adenomas experience at a single center: clinical importance of AIP mutation screening
}

\author{
Experiência de um único centro em adenoma hipofisário familiar \\ isolado: importância clínica do rastreio de mutação do AIP
}

\begin{abstract}
Leandro Kasuki Jomori de Pinho ${ }^{1,2}$, Leonardo Vieira Neto, Luiz Eduardo Armondi Wildemberg', Aline Barbosa Moraes ${ }^{1,2}$, Christina M. Takiya ${ }^{4}$, Lawrence A. Frohman ${ }^{5}$, Márta Korbonits's, Mônica R. Gadelha' ${ }^{1,2}$
\end{abstract}

1 Endocrinology Service, Hospital Universitário Clementino Fraga Filho (HUCFF), Rio de Janeiro, RJ, Brazil ${ }^{2}$ Instituto Estadual de Diabetes e Endocrinologia Luiz Capriglione (lede), Rio de Janeiro, Brazil

${ }^{3}$ Endocrinology Service, Hospital da Lagoa, Rio de Janeiro, RJ, Brazil ${ }^{4}$ Laboratory of Cellular Pathology, Universidade Federal do Rio de Janeiro (UFRJ), Rio de Janeiro, RJ, Brazil

${ }^{5}$ Section of Endocrinology, Department of Medicine, University of Illinois at

Chicago, Chicago, III, USA ${ }^{6}$ Department of Endocrinology, Barts and the London School of Medicine, London, Queen Mary University of London, UK

\section{Correspondence to: Mônica R. Gadelha Centro de Pesquisa em Neuroendocrinologia Rua Professor Rodolpho Paulo Rocco, 255, sala 9F \\ 21941-913 - Rio de Janeiro, RJ, Brazil \\ mgadelha@hucff.ufri.br}

\section{SUMMARY}

We present four FIPA kindred discussing clinical and molecular data and emphasizing the differences regarding AIP status, as well as the importance of genetic screening. Family 1 consists of five patients harboring somatotropinomas with germline E24X mutation in AIP. In one of the patients, acromegaly was diagnosed through active screening, being cured by surgery. Families 2 and 3 are composed of two patients with non-functioning pituitary adenomas. Family 4 comprises patients harboring a prolactinoma and a somatotropinoma. No mutations in AIP were found in these families. No patient in Family 1 was controlled with octreotide treatment, while the acromegalic patient in Family 4 was controlled with octreotide LAR. In conclusion, FIPA is a heterogeneous condition, which may be associated with AIP mutation. Genomic and clinical screening is recommended in families with two or more members harboring pituitary adenomas, allowing early diagnosis and better outcome. Arq Bras Endocrinol Metab. 2010;54(8):698-704

\section{SUMÁRIO}

Apresentamos dados clínicos e moleculares de quatro famílias com adenoma hipofisário familiar isolado (FIPA) enfatizando as diferenças na presença ou não de mutação do AIP e a importância da triagem genética. A Família 1 é composta por cinco pacientes portadores de somatotropinomas com mutação germinativa E24X no AIP. Um dos pacientes foi diagnosticado por meio de rastreio ativo, com cura cirúrgica. As Famílias 2 e 3 apresentam em sua composição dois pacientes com adenomas hipofisários não funcionantes. A Família 4 compreende dois pacientes, um com prolactinoma e outro com somatotropinoma. Não foi encontrada mutação no AIP nessas famílias. Na Família 1, não houve resposta ao octreotide, enquanto o paciente acromegálico da Família 4 foi controlado com a medicação. Em conclusão, a FIPA é uma condição heterogênea que pode estar associada à mutação do AIP e o rastreio genético/clínico é recomendado nas famílias com dois ou mais membros portadores de adenoma hipofisário. Isso permite um diagnóstico precoce, com melhor prognóstico. Arq Bras Endocrinol Metab. 2010;54(8):698-704

\section{INTRODUCTION}

$\mathrm{P}$ ituitary adenomas are usually sporadic, although familial syndromes account for at least $5 \%$ of these tumors (1). In such cases, they may occur as part of a multiple endocrine neoplasia syndrome [multiple endocrine neoplasia type 1 (MENl), multiple endocrine neoplasia type 4 or Carney complex (CNC)] or also as familial isolated pituitary adenomas (FIPA) (2-4). The
FIPA syndrome is characterized by the presence of two or more pituitary adenomas in a family in the absence of a multiple endocrine neoplasia syndrome and may present a homogeneous or heterogeneous pattern depending on whether the family harbors the same or different pituitary adenoma subtypes (3). The most significant homogeneous FIPA is the isolated familial somatotropinoma (IFS), defined by Gadelha and cols. (5), in 1999, 
as the presence of two or more cases of acromegaly and/or gigantism in a family without the diagnosis of MENl or CNC.

In 1995, Benlian and cols. (6) established that there must be a novel genetic cause for low-penetrance familial pituitary adenomas in a study assessing a FIPA family with MENl negative somatotropinomas. The study concluded that there was a low-penetrance causative gene close to the MENI locus. Yamada and cols. (7) reported a loss of heterozygosity ( $\mathrm{LOH}$ ) on chromosome 1lq13 in a family with IFS in 1997 and subsequently Tanaka and cols. (8) demonstrated the absence of mutations in the MEN1 gene in the same family, suggesting that another gene was involved in the pathogenesis of IFS. Gadelha and cols. (9), in 2000, through the analysis of two families with IFS described the linkage of the tumor suppressor gene involved in the pathogenesis of the disease to chromosome 1lq13.1-13.3. Vierimaa and cols. (10) in 2006 described a mutation in a gene located in this region. The group described a nonsense germline mutation $(\mathrm{Q} 14 \mathrm{X})$ in the coding region of the aryl hydrocarbon receptor-interacting protein $(A I P)$ gene in two Finnish families with FIPA. One family had cases of prolactinomas and somatotropinomas, and the other had only somatotropinomas. $\mathrm{LOH}$ analysis was performed in eight patients with mutation (five somatotropinomas, a mammosomatotroph tumor and two prolactinomas) and it was detected in all patients. Mutations in $A I P$ are described in $50 \%$ of the IFS patients and in $15 \%-40 \%$ of the FIPA families (1,2,11-13), although multiplex-ligation dependent probe amplification (MLPA) and promoter sequencing were only performed in some series $(12,14)$, therefore, a slightly higher percentage may actually occur.

The AIP gene consists of 6 exons and codes for a 330 amino acid co-chaperone protein (1). This protein is made up of two domains, the $\mathrm{N}$-terminal FKBP domain and the $\mathrm{C}$-terminal domain containing three tetratricopeptide repeats, each consisting of 34 amino acid residue-conserved repeats each forming two $\alpha$-helices (helices A and B) and a terminal A-type $\alpha$-helix (1,1213). The C-terminal domain is required for binding to the aryl hydrocarbon receptor (AHR), while the $\mathrm{N}$-terminal domain contributes to the stability of the AHRHSP90-AIP complex and regulation of its intra-cellular localization (12).

Leontiou and cols. (15) demonstrated that AIP has properties consistent with a tumor suppressor gene. Wild type AIP attenuated cell proliferation in three dif- ferent cell lines, while transfection of two AIP variants (R304X and C238Y) had no or reduced ability to block proliferation in these cell lines. They also observed that mutant AIP loses the capacity to bind to PDE4A5 and its effect to modulate cAMP. However, the exact mechanisms by which AIP exerts its tumor-suppressive action remain to be established.

In this article, we describe four families with FIPA, one with an AIP mutation, emphasizing the differences in clinical presentation of the disease in families with and without a mutation and discuss the practical relevance of these $A I P$ data to the clinical endocrinologist.

\section{SUBJECTS AND METHODS}

This study was approved by the Ethics Committee of the Hospital Universitário Clementino Fraga Filho/ Universidade Federal do Rio de Janeiro. All families reported are currently being followed-up at this hospital, and all subjects signed an informed consent form before study entry. There was no history of consanguinity, and the clinical history and laboratory results excluded a multiple endocrine neoplasia syndrome in all affected and unaffected screened subjects.

\section{ANALYSIS OF AIP MUTATION}

Genomic deoxyribonucleic acid (DNA) was extracted using QIAamp DNA MiniKit (Qiagen, Valencia, CA) from peripheral white blood cells, according to manufacturer's protocol. The entire coding sequence of AIP (NM_003977.2), conserved splice sites (from the conserved $A$ of the upstream branch site to +10 downstream of each exon) and 1200 base-pairs of the promoter region were direct sequenced. The MLPA (P244-kit MRC-Holland, Amsterdam, Netherlands) dosage analysis was carried out to look for partial or whole gene deletions in all the families that tested negative by direct sequencing for germline AIP mutations and from whom a suitable quality of DNA sample was available. DNA was denatured at $98^{\circ} \mathrm{C}$ for 5 minutes and cooled to $25^{\circ} \mathrm{C}$ at a thermocycler. A hybridization mix $(1.5 \mu \mathrm{L}$ MLPA buffer $+1.5 \mu \mathrm{L}$ probemix $)$ was added to the sample, followed by a ligase master mix (Ligase-65 buffer A). A PCR buffer mix was added to the ligand product and PCR was performed according to the manufacture's instructions (MCR-Holland). For more details please consult reference 12 . 


\section{RESULTS}

\section{Family characterization}

Demographic, laboratorial data and tumor size of affected subjects are described in table 1 .

\section{Families with homogeneous FIPA}

\section{Family 1}

Family $\mathrm{l}$ has five patients affected by somatotropinomas (Figure 1). The index case, patient 4 , was diagnosed with acromegaly at 24 years of age, with symptoms starting four years before. All other affected subjects were diagnosed between the ages of 13-17. Patient 11 was diagnosed through active screening after the detection of LOH on locus $1 \mathrm{lql}$. He had a mild disease and a small tumor, and was cured by surgery. All other subjects harbored an invasive macroadenoma. For more details please consult references 5 and 12 - Supp. Table S2, family II.

\section{Family 2}

Family 2 has two patients with non-functioning pituitary adenomas (NFPA), one female patient with a silent corticotroph adenoma (index case) diagnosed at 28 years of age and her father who had a diagnosis of NFPA (Figure 2). No more information regarding this latter patient is available because he was deceased at the time of his daughter's diagnosis. The first patient harbored a noninvasive macroadenoma and surgery was felt to be curative. No tumor recurrence was observed after two years of follow-up.

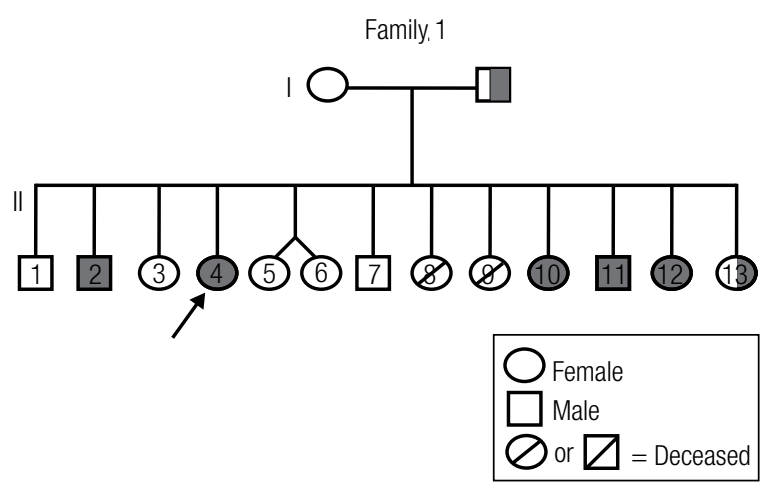

Figure 1. The genealogical tree of Family 1. Arrow: index case. Gray-filled symbols represent acromegaly or gigantism; half-filled symbols represent carrier subjects.

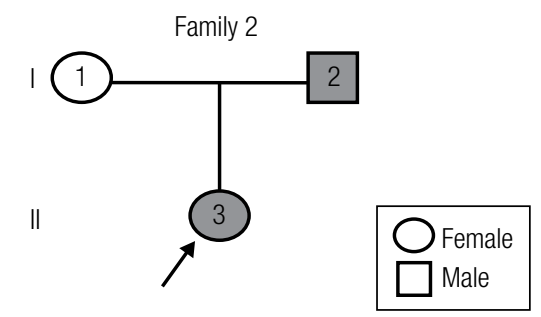

Figure 2. The genealogical tree of Family 2. Arrow: index case. Gray-filled symbols represent non-functioning pituitary adenomas.

Table 1. Demographic and laboratory data, and tumor size of affected subjects from FIPA families

\begin{tabular}{|c|c|c|c|c|c|c|c|c|}
\hline Patients & Sex & $\begin{array}{c}\text { Age at } \\
\text { Diagnosis (yr) }\end{array}$ & $\begin{array}{c}\mathrm{GH}^{\mathrm{b}} \\
(\mathrm{ng} / \mathrm{mL})\end{array}$ & $\begin{array}{c}\text { IGF-I } \\
(\mathrm{ng} / \mathrm{mL})\end{array}$ & $\begin{array}{c}\text { IGF-I } \\
\text { Normal range }\end{array}$ & $\begin{array}{l}\text { Prolactin } \\
(\mathrm{ng} / \mathrm{mL})^{\mathrm{c}}\end{array}$ & Size tumor ${ }^{d}$ & Phenotype \\
\hline \multicolumn{9}{|l|}{ Family 1} \\
\hline 2 & M & 17 & 34 & 767 & 199-795 & 40 & MAC & Gigantism \\
\hline 4 & $F$ & 24 & 74 & 500 & $116-341$ & 14 & MAC & Acromegaly \\
\hline 10 & $\mathrm{~F}$ & 15 & 65 & 495 & 238-917 & 11 & MAC & Gigantism \\
\hline 11 & M & 17 & 8.3 & 542 & 199-795 & 9.0 & MIC & Acromegaly \\
\hline 12 & $F$ & 13 & 24 & 965 & $180-905$ & 16 & MAC & Gigantism \\
\hline \multicolumn{9}{|l|}{ Family 2} \\
\hline 2 & M & NA & NA & NA & NA & NA & MAC & NFPA \\
\hline 3 & $F$ & 28 & NA & 181 & $117-321$ & $72,6^{e}$ & MAC & NFPA \\
\hline \multicolumn{9}{|l|}{ Family 3} \\
\hline 1 & M & 54 & 0,11 & 128 & $84-233$ & $45,9^{e}$ & MAC & NFPA \\
\hline 3 & M & 44 & NA & NA & NA & NA & MAC & NFPA \\
\hline \multicolumn{9}{|l|}{ Family 4} \\
\hline 3 & $\mathrm{~F}$ & 24 & NA & NA & NA & $>1,500$ & MAC & Prolactinoma \\
\hline 6 & M & 46 & 3.4 & 555 & $91-246$ & 91.4 & MAC & Acromegaly \\
\hline
\end{tabular}

a. M: Male; F: Female. b. Random GH. c. Normal values: females $2.0-23 \mathrm{ng} / \mathrm{mL}$ and males 2.0- $15.0 \mathrm{ng} / \mathrm{mL}$. d. MIC: Microadenoma ( $\leq 1 \mathrm{~cm}) ;$ MAC: Macroadenoma (> $1 \mathrm{~cm})$. e. Diluted prolactin NA: not available. NFPA: Non-functioning pituitary adenoma. 


\section{Familly 3}

Family 3 has two patients, both harboring non-functioning macroadenomas (Figure 3 ). One patient was diagnosed at 54 years of age (index case) and the tumor was an invasive NFPA positive for FSH on immunostaining. The other patient was diagnosed at 44 years of age and the tumor was a noninvasive NFPA positive for $\mathrm{LH}$ and $\mathrm{FSH}$ immunostaining.

\section{Family with heterogeneous FIPA}

\section{Familly 4}

Family 4 has two affected members (Figure 4). One female patient with an invasive macroprolactinoma diagnosed at age of 24 and her nephew who was diagnosed with acromegaly at the age of 46 (index case). He harbored an invasive macroadenoma, and surgery was not felt to be curative. The tumor showed positive immunostaining for $\mathrm{GH}$ in more than $90 \%$ of the cells and for prolactin in $100 \%$ of the cells.

\section{Analysis of AlP mutation}

In family $\mathrm{l}$, AIP mutation (E24X, c.70G $>\mathrm{T}$, GenBank accession number EF643644) was present in all affected subjects, in the father who is an obligate carrier, and in one of the siblings not affected at the time of the study. MLPA dosage was normal (for details please consult reference 12). No mutation was identified in AIP and MLPA dosage was normal in families 2 and 3 (for more details please consult reference 12, Supp. Table S1, Family 19 and 20, respectively). Similarly, in Family 4, no mutation was identified in AIP and MLPA dosage was normal.

\section{Comparison between families with or without AIP mutations}

Median age was 17 years of age (range 13-24y) in $A I P$ positive family and 44 years of age (24-54y) in AIPnegative families. Acromegaly or gigantism was present in all cases in the $A I P$-positive family and in $17 \%$ ( 1 out of 6$)$ of the affected subjects in the $A I P$-negative families. In Family 1 ( $A I P$-positive) patient 11 did not present disease recurrence after 11 years of follow-up. All the subjects that harbored a macroadenoma were not cured by surgery, did not respond to octreotide and were treated by radiotherapy. The acromegalic patient in Family 4, despite having moderately elevated GH and IGF-I, did not respond to cabergoline treatment $(2.5$ mg per week), so octreotide LAR was started $(20 \mathrm{mg}$ every 28 days) with normalization of GH and IGF-I.
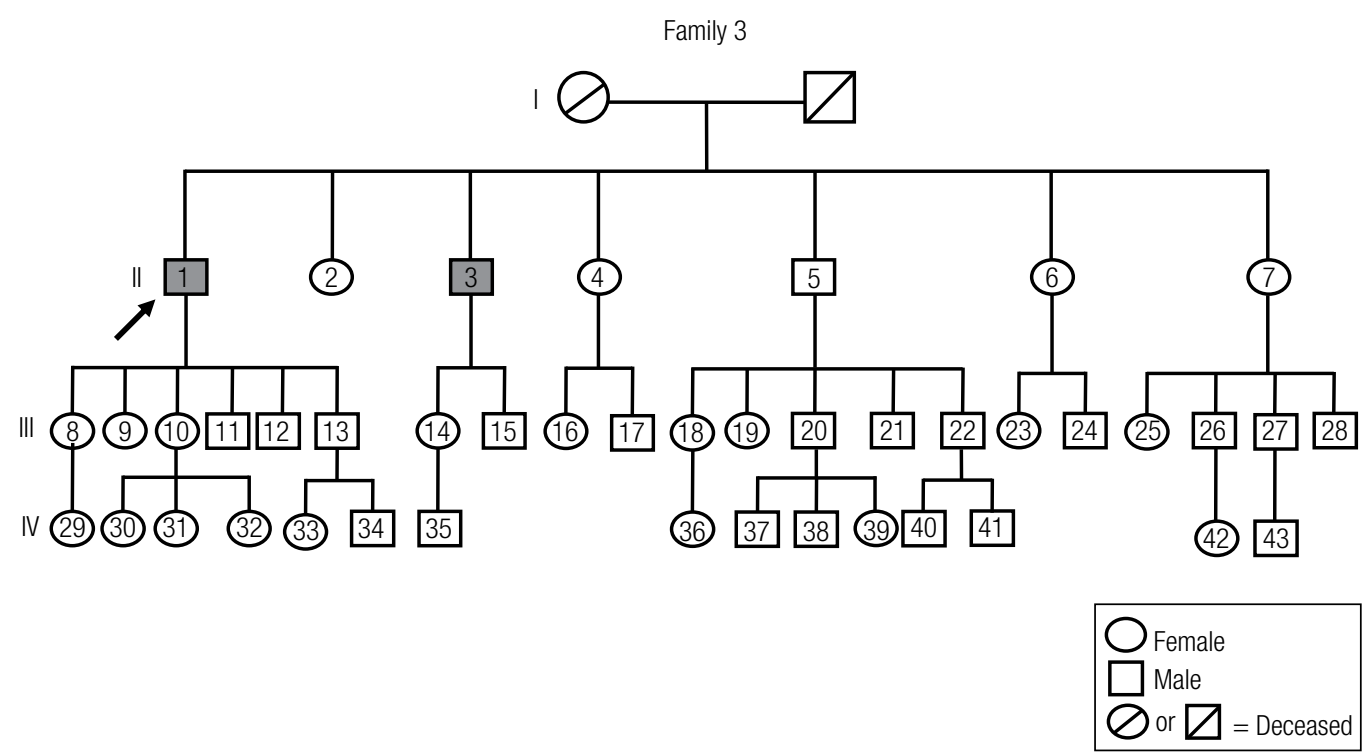

Figure 3. The genealogical tree of Family 3. Arrow: index case. Gray-filled symbols represent non-functioning pituitary adenomas. 


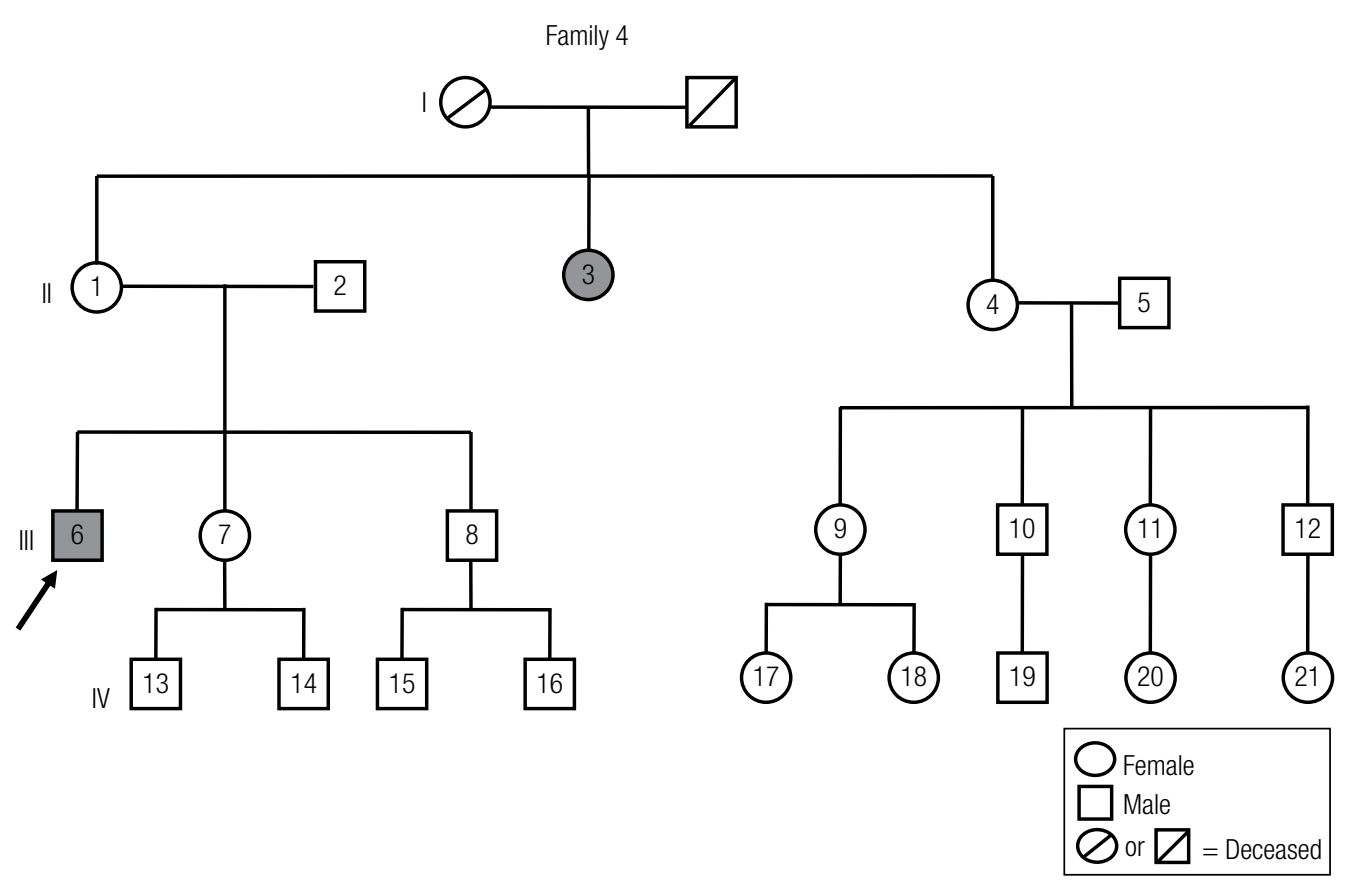

Figure 4. The genealogical tree of Family 4. Arrow: index case. Gray-filled symbol represents acromegaly and gray-filled symbol represents prolactinoma.

\section{DISCUSSION}

In our series, an $A I P$ mutation was present in $25 \%$ of the FIPA families, similar to the literature (2,11-12). The only AIP-positive family presented exclusively with somatotropinomas. In the families without $A I P$ mutations, other adenoma subtypes were present, including two families without cases of acromegaly. In FIPA kindred without AIP mutations, prolactinomas are generally the most frequent subtype $(41 \%)$, while somatotropinomas occur in $30 \%$ of the patients (2). In contrast, most cases of FIPA with an AIP mutation are somatotropinomas $(82 \%)$, while prolactinomas account for only $11 \%$ (2). Other adenoma subtypes (corticotropinoma and non-functioning pituitary adenoma) are extremely rare in cases with mutations in this gene (1-2). In our series, the prevalence of acromegaly and prolactinoma in FIPA without AIP mutation is $17 \%$ ( 1 out of 6) each, beneath that described in the literature.

With respect to age, patients with FIPA without an AIP mutation are usually older at the time of diagnosis than those with a mutation (1,11-13). Igreja and cols. (12) described that the majority of their families with an AIP mutation had at least one member with gigantism and/or disease onset below 18 years of age, while it was present in only three out of $44 A I P$-negative FIPA families. In our series, gigantism and/or disease onset prior to 18 years of age were only observed in the family with an AIP mutation. In addition, the median age at diagnosis in this family was 17 years of age (range 13-24y), while in the $A I P$-negative families it was 44 years of age (24-54y).

Patients with $A I P$ mutations usually present with a more aggressive disease, with invasive adenomas, have a low chance of surgical cure and a poorer response to available medical treatments, such as somatostatin analogues (SA) in acromegaly $(12,13)$. The use of SA results in disease control in approximately 50\%-60\% of sporadic acromegalic patients (16). In our series, none of the patients in Family 1 (AIP-positive) who were treated with octreotide responded to the drug. In contrast, the acromegalic patient in Family 4 was controlled with a standard dose of octreotide LAR (20 mg every 4 weeks).

The majority of patients with AIP mutations harbor macroadenomas (97\%) (11). There is one patient with a microadenoma in our $A I P$-positive family but, in this case, the genetic alteration was detected before clinical diagnosis of acromegaly. He presented with a mild 
disease, with moderately elevated GH and IGF-I, suggesting that he was diagnosed at an early stage, which could explain the small tumor size.

In the above described patient, the early diagnosis led to surgical cure, showing the importance of disease screening in AIP mutated subjects. We recommend performing a basal prolactin and IGF-I measurement, as well as an oral glucose tolerance test for GH suppression, and pituitary magnetic resonance imaging. In $A I P$-negative FIPA families, members with a $50 \%$ chance of inheriting the disease should be counseled about the low-penetrance of the disease, and the need for clinical and biochemical testing and imaging can be discussed (1).

We did not find mutations in the AIP gene in families 2-4, but this cannot exclude the possibility of a mutation in an intronic region. Nevertheless, the reported differences between patients with and without AIP mutations suggest the role of other gene(s) in the pathogenesis of $A I P$ negative FIPA.

Due to the frequency described in the literature $(2,12)$, screening for AIP mutations in patients with any type of isolated pituitary adenoma occurring in a familial setting is recommended; possibly, IFS and families with somatotropinomas and prolactinomas should be targeted first (11). In sporadic pituitary adenomas, the occurrence of $A I P$ mutations is much less frequent $(17,18)$. However, it has been previously described that younger patients with somatotropinomas have a higher frequency of germline mutations, especially those less than 25 years old $(19,20)$. Thus, it seems reasonable to screen young patients with apparently sporadic invasive somatotropinomas or prolactinomas for $A I P$ mutations. If a mutation is detected in this setting, the patient's family members should be screened for the AIP mutation and asymptomatic carriers should be investigated as previously described.

In conclusion, FIPA is a heterogeneous condition, which may be associated with AIP mutation and genomic and clinical screening is recommended in families with two or more members harboring pituitary adenomas. This disease screening allows early diagnosis in these subjects and, consequently, better outcome.

Disclosure: no potential conflict of interest relevant to this article was reported.

Acknowledgments: We thank Drs. Sian Ellard and Karen Stals for performing AIP mutation analysis at the Department of Molecular Genetics of Royal Devon and Exeter Foundation Trust.

\section{REFERENCES}

1. Chahal HS, Chapple JP, Frohman LA, Grossman AB, Korbonits M. Clinical, genetic and molecular characterization of patients with familial isolated pituitary adenomas (FIPA). Trends Endocrinol Metab. 2010;21(7):419-27.

2. Beckers A, Daly AF. The clinical, pathological, and genetic features of familial isolated pituitary adenomas. Eur $\mathrm{J}$ Endocrinol. 2007;157(4):371-82.

3. Daly $A F$, Jaffrain-Rea $M L$, Ciccarelli $A$, Valdes-Socin $H$, Rohmer V, Tamburrano G, et al. Clinical characterization of familial isolated pituitary adenomas. J Clin Endocrinol Metab. 2006;91(9):3316-23.

4. Pellegata NS, Quintanilla-Martinez L, Siggelkow H, Samson E, Bink K, Höfler H, et al. Germ-line mutations in p27Kip1 cause a multiple endocrine neoplasia syndrome in rats and humans. Proc Natl Acad Sci U S A. 2006;103(42):15558-63.

5. Gadelha MR, Prezant TR, Une KN, Glick RP, Moskal SF 2nd, Vaisman $\mathrm{M}$, et al. Loss of heterozygosity on chromosome $11 \mathrm{q} 13$ in two families with acromegaly/gigantism is independent of mutations of the multiple endocrine neoplasia type I gene. J Clin Endocrinol Metab. 1999;84(1):249-56.

6. Benlian P, Giraud S, Lahlou N, Roger M, Blin C, Holler C, et al. Familial acromegaly: a specific clinical entity--further evidence from the genetic study of a three-generation family. Eur J Endocrinol. 1995;133(4):451-6.

7. Yamada S, Yoshimoto K, Sano T, Takada K, Itakura M, Usui M, et al. Inactivation of the tumor suppressor gene on $11 \mathrm{q} 13$ in brothers with familial acrogigantism without multiple endocrine neoplasia type 1. J Clin Endocrinol Metab. 1997;82(1):239-42.

8. Tanaka C, Yoshimoto K, Yamada S, Nishioka H, Li S, Moritani $M$, et al. Absence of germ-line mutations of the multiple endocrine neoplasia type 1 (MEN1) gene in familial pituitary adenoma in contrast to MEN1 in Japanese. J Clin Endocrinol Metab. 1998;83(3):960-5.

9. Gadelha MR, Une KN, Rohde K, Vaisman M, Kineman RD, Frohman LA. Isolated familial somatotropinomas: establishment of linkage to chromosome 11q13.1-11q13.3 and evidence for a potential second locus at chromosome 2p16-12. J Clin Endocrinol Metab. 2000;85(2):707-14.

10. Vierimaa O, Georgitsi M, Lehtonen R, Vahteristo P, Kokko A, Raitila $A$, et al. Pituitary adenoma predisposition caused by germline mutations in the AIP gene. Science. 2006;312(5777):1228-30.

11. Cazabat $L$, Guillaud-Bataille $M$, Bertherat J, Raffin-Sanson ML. Mutations of the gene for the aryl hydrocarbon receptor-interacting protein in pituitary adenomas. Horm Res. 2009;71(3):132-41.

12. Igreja S, Chahal HS, King P, Bolger GB, Srirangalingam U, Guasti $L$, et al. Characterization of aryl hydrocarbon receptor interacting protein (AIP) mutations in familial isolated pituitary adenoma families. Hum Mutat. 2010;31(8):950-60.

13. Gadelha MR, Frohman LA. Pathogenesis of familial acromegaly. Front Horm Res. 2010;38:121-6.

14. Georgitsi M, Heliövaara E, Paschke R, Kumar AV, Tischkowitz $\mathrm{M}$, Vierimaa $\mathrm{O}$, et al. Large genomic deletions in AIP in pituitary adenoma predisposition. J Clin Endocrinol Metab. 2008;93(10):4146-51.

15. Leontiou CA, Gueorguiev M, van der Spuy J, Quinton R, Lolli F, Hassan S, et al. The role of the aryl hydrocarbon receptor-interacting protein gene in familial and sporadic pituitary adenomas. $J$ Clin Endocrinol Metab. 2008;93(6):2390-401.

16. Murray RD, Melmed S. A critical analysis of clinically available somatostatin analog formulations for therapy of acromegaly. $J$ Clin Endocrinol Metab. 2008;93(8):2957-68.

17. Barlier A, Vanbellinghen JF, Daly AF, Silvy M, Jaffrain-Rea ML, Trouillas $\mathrm{J}$, et al. Mutations in the aryl hydrocarbon receptor in- 
teracting protein gene are not highly prevalent among subjects with sporadic pituitary adenomas. J Clin Endocrinol Metab. 2007;92:1952-5.

18. Raitila A, Georgitsi M, Karhu A, Tuppurainen K, Makinen MJ, Birkenkamp-Demtroder $\mathrm{K}$, et al. No evidence of somatic aryl hydrocarbon receptor interacting protein mutations in sporadic endocrine neoplasia. Endocrine-Related Cancer. 2007;14(3):901-6.

19. Cazabat L, Libe $R$, Perlemoine K, Rene-Corail F, Burnichon N, Gimenez-Roqueplo AP, et al. Germline inactivating mutations of the aryl hydrocarbon receptor-interacting protein gene in a large cohort of sporadic acromegaly: mutations are found in a subset of young patients with macroadenomas. Eur J Endocrinol. 2007;157(1):1-8.

20. Stratakis CA, Tichomirowa MA, Boikos S, Azevedo MF, Lodish M, Martari $M$, et al. The role of germline AIP, MEN1, PRKAR1A, CDKN1B and CDKN2C mutations in causing pituitary adenomas in a large cohort of children, adolescents, and patients with genetic syndromes. Clin Genet. 2010;78(5):457-63. 